\title{
TOWARD A PRACTICAL FORMULATION OF CSV PROGRAM
}

\author{
Woonghee Lee, Hanyang University, Seoul, Korea
}

dx.doi.org/10.18374/JABE-19-3.6

\begin{abstract}
The notion of CSV(Creating Shared Value) has recently received criticisms based on its redundancy with previous concepts such as â€ â€ strategic CSR' and â€年lended value'. In addition to these conceptual problems, this paper suggests that there exist practical problems in CSV formulation because many of CSV examples reported are in fact, â€ usual managerial activities', that seem too general to apply in real business settings. To avoid these practical problems, three solutions are suggested in this paper. First, a firm should adopt a differentiated approach to produce a significant economic and social impact. Second, by focusing on a specific social segment of the market, a new product or service introduction under CSV program should significantly increase economic and social return. In the third, direct government involvement in CSV should be avoided because it impairs original purpose of CSV.
\end{abstract}

Keywords: CSV, Shared Value, Formulation 